\title{
The ICRC at a crossroads: Swiss roots-international outlook
}

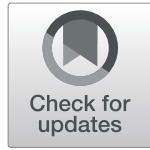

\author{
Claudia Franziska Brühwiler ${ }^{1^{*}} \mathbb{D}$, Patricia Egli ${ }^{2}$ and Yvette Sánchez $^{3}$
}

\begin{abstract}
The International Committee of the Red Cross (ICRC) has undergone a considerable transformation in the recent decades: from being driven by a pre-dominantly Swiss body of employees, it has become an organization dominated by international staff that hail from all over the world. While the leadership is still firmly in Swiss hands, the transformation has put into question to what extent the ICRC has been able to uphold its foundational values and its special relationship with Swiss culture. The strong ties with Swiss values such as neutrality, independence, consensus, reliability, work ethics, and participation used to be perceived as key factors for the organization's continuity and success in delivering humanitarian aid in a politically more and more divided world. Indeed, from a historical perspective, the Swiss rootedness shaping the organizational culture and identity allowed the ICRC to be successful in its endeavors as a neutral humanitarian actor even in times of crises. This paper, through an analysis of interviews with ICRC staff members of different nationalities, seeks to explore to what extent Swiss values are perceived to still matter in the ICRC, its humanitarian work and how Swiss and non-Swiss staff members interpret these values. The research suggests that there are three distinct narratives, namely, an internationalist, a traditionalist, and a pragmatist. While the internationalist narrative perceives the ICRC's internationalization as a positive development for the organization as a whole, the traditionalist is concerned about detrimental effects on the organizational culture as well as on the credibility of the humanitarian work in the field. The pragmatist narrative recognizes the benefits of strong Swiss values in the ICRC, yet highlights that current developments call for internationalization. The study extends our understanding of the importance of core organizational values and principles in a process of internationalization in order to stay a credible and successful humanitarian actor.
\end{abstract}

Keywords: Humanitarianism, International Committee of the Red Cross (ICRC), Organizational culture, Organizational values and principles, Swissness, Switzerland, Values

\section{Introduction}

"The Swiss never take sides. [...] We are only on the side of the Swiss," a delegate of the International Committee of the Red Cross (ICRC) claims in Ann Patchett's novel Bel Canto (2002: 88). Dry, matter-of-fact, aloof even, yet efficient, reliable, and empathetic: the image the author draws of the delegate resonates with commonly held views of the Swiss, Switzerland, and arguably its bestknown organization, the ICRC. As one of the first independent scholars to gain access to the ICRC's archives, Caroline Moorehead marveled at her research subject's enigmatic nature, the many contradictions it embodies:

\footnotetext{
* Correspondence: claudia-franziska.bruehwiler@unisg.ch

${ }^{1}$ School of Economics and Political Science (SEPS) and School of Humanities and Social Sciences (SHSS), University of St. Gallen, Müller-Friedbergstrasse 6/ 8, 9000 St. Gallen, Switzerland

Full list of author information is available at the end of the article
}

"Like a riddle, the signals it gives out are contradictory. The International Committee... calls itself international; yet is a private Swiss company, based in Geneva and governed by twenty-five Swiss citizens" (Moorehead 1998: xxi). ${ }^{1}$ Indeed, the ICRC's historic roots, legal foundations, its institutional idiosyncrasies, and its organizational culture reflect tight links with the organization's national home base, the Swiss Confederation. Founded in Geneva in 1863 as a private initiative, the ICRC waves its flags in over 80 countries all over the world, with 18,600 staff members fulfilling its international mandate. The organization has strong ties with the Swiss state, and Swiss citizens dominate its leadership, but the ICRC, overall, has undergone a transformation in terms of internationalization of staff and decentralization of operations. In fact, most of ICRC employees nowadays hail from countries other 
than Switzerland and the language of choice is often English instead of French. Moreover, the organization decided to adapt its structure and management processes to keep up with its own growth and the changing challenges of humanitarian operations. One may thus wonder: how Swiss is the ICRC today? And how Swiss should the ICRC be in order to successfully continue its humanitarian action?

These questions are at the heart of our study. Specifically, we consider the tension between the ICRC's rootedness in Swiss culture as a key factor for the organization's continuity and success in delivering humanitarian aid and its increasingly international staff. We inquire whether Swiss values still affect the institutional structure, the organizational culture, the ICRC's humanitarian work, and the perception of the ICRC by its staff. Consequently, the article first takes stock of the existing literature on the relationship between the ICRC, the Swiss federal state, and Swiss values. It then discusses the concept of "value" and presents a framework of categories. In the third section, we present the findings of our empirical study, showing, on the one hand, what is commonly associated with Swiss values and, on the other, to what extent these assumptions enter the organization and its humanitarian action.

\section{The ICRC's Swiss roots and rootedness Legal status}

The ICRC is an entity unlike any other in the field of humanitarian action: neither a non-governmental organization nor an international, intergovernmental, or transnational organization, it is, as its own legal division argues, "in a class of its own" (Rona 2004). According to its Statutes, the "ICRC is an association governed by Article 60 and following of the Swiss Civil Code" (Art. 2 para. 1), i.e., it is subject to the same laws as any student club or municipal sports' association. Its specificity accrues from Art. 2 para. 2 of the Statutes which stipulates that it also "enjoys a status equivalent to that of an international organization and has international legal personality in carrying out its work." As a consequence, it is of a hybrid legal nature-at once very Swiss in that it shares the same legal roots as the pillars of Swiss civil society, yet it is set apart by its internationally privileged status other humanitarian organizations do not benefit from.

To secure its independence from the Swiss Confederation, the ICRC and the Federal Council concluded an "Agreement between the International Committee of the Red Cross and the Swiss Federal Council to determine the legal status of the Committee in Switzerland" in 1993, commonly referred to as the Headquarters Agreement. Therein, the Federal Council "recognizes the international juridical personality" of the ICRC (Art. 1) and "guarantees the ICRC independence and freedom of action" (Art. 2).

\section{The ICRC and the Swiss Confederation}

Former Federal Councilor Marcel Pilet-Golaz (1889-1958) once claimed that "for Bern in principle what is good for the Red Cross is good for Switzerland" (qtd. in Forsythe 2005: 184). His words faintly echo in former Federal Councilor Johann Schneider-Ammann's speech, honoring the 150th anniversary of the Swiss Red Cross, in which he argued that the "Red Cross embodies Swiss values" (Schneider-Ammann 2016: np; own translation). This tight relationship is underlined, thus Schneider-Ammann, by the emblem itself, a reversal of the Swiss national flag. While the emblem was at the ICRC's inception not intended to celebrate the Confederation, but rather to "represent both personal Christian charity and the universal aspirations of enlightened humanitarianism" (Hutchinson 1996: 143), the links between the Swiss state and the ICRC used to be tight-too tight, some would add. Even in the latest Federal Council's report on the goals of Swiss international cooperation in the years 2017-2020, the "special relationship" with the ICRC is highlighted (Schweizerische Eidgenossenschaft 2016: 2408).

The close relationship is, firstly, by institutional design. Legal scholar David P. Forsythe goes as far as likening the early ICRC to a GONGO, a governmentally organized non-governmental organization (Forsythe 2005: 169), a verdict that, though unnecessarily harsh in tone, cannot be refuted easily. Early on, the ICRC-as well as the national Red Cross organizations-sought to act jointly with states, operating only with state consent, and did not object to being treated as the humanitarian arm of the Swiss Confederation (Forsythe 2005: 190). As a consequence, the ICRC at times struggled to distinguish between its own interests, i.e., its mandate, and the interests of Switzerland, particularly up to the end of World War II (Gasser 2003: 121).

Such entanglements were accentuated, secondly, by the fact that for a long time many members of the ICRC's supreme governing body, the assembly, were simultaneously active in politics or in the federal administration. As Philippe Bender (1991) puts it: "There is a kind of osmosis, a similarity of views between their respective leaders that have established a privileged relationship-going beyond their formal links under the law-between the National Society and the economic, political and military powers that be" (1991: 362-363). The lacking separation of offices proved disastrous during World War II. When Federal Councilor Philippe Etter served on the ICRC Assembly and, instead of supporting the organization and addressing information on the German concentration camps, ${ }^{3}$ he pursued the Confederation's policy: “The ICRC therefore caved in to Swiss national interests as defined in Bern, sacrificing the independence and humanitarian values of the organization" (Forsythe 2005: 48; see Gasser 2003: 121). 
During the Cold War, the ICRC also dealt with attempts by the Swiss government to use the Red Cross on behalf of the white cross, yet increasing professionalization and the exclusion from active politicians or government officials from the assembly weakened the ties. The presidency, however, still goes frequently to former Swiss diplomats or high-ranking members of the federal administration. This is unlikely to change: "As long as there is no broader source of experienced international personnel with Swiss nationality, suitable candidates will have to be found in Bern rather than elsewhere" (Gasser 2003: 122).

Moreover, as Schneider-Ammann's words and the latest report on Swiss international cooperation convey, the Swiss government likes to underline the historically close relationship between the Confederation and the ICRC, not only because it serves to "broaden the rather narrow scope of Switzerland's own foreign policy" (Gasser 2003: 120), but also due to the perception that humanitarianism is part of the country's core foreign policy values. Fanzun described humanitarian engagement as both "a natural complement to and ... a legitimization of neutrality" (Fanzun 2003: 130). Consequently, the ICRC features in the communication efforts by the Federal Department of Foreign Affairs which references the Red Cross in its strategy outlines (FDFA 2016) and highlights its support for "international Geneva" (Presence Switzerland 2019: 12).

\section{Mono-national leadership}

Mirroring its legal uniqueness, the ICRC has likewise established an unusual process to recruit its leadership, the assembly. According to the Statutes, the members "shall be co-opted from among Swiss citizens" (Art. 7 para. 1). Consequently, members do not only have to share the same nationality, but also co-optation as a recruiting mechanism leads to other commonalities, at least with respect to the social and professional circles the assembly members move in. These institutional choices reflect the early years of the ICRC.

The ICRC's founders, "the original five" (Palmieri 2012: 1275), were driven by the same spirit: "Genevan exceptionalism," Forsythe argues in his seminal treatise, led to "the collective self-image, no doubt partially the product of Calvinism, that the citizens of Geneva constituted a special people with a positive role to play in the larger world" (2005: 17). Henry Dunant, Gustave Moynier, Théodore Maunoir, Louis Appia, and General Guillaume Henri Dufour shared not only the same home-town and the same worldview, but they were all Protestants and members of the same social class (Forsythe 2005: 175; Palmieri 2012: 1275). Co-optation led, for a long time, to self-replication, as the new members resembled their predecessors in origin, class, religion, and gender, often even related to each other (Forsythe 2005: 203; Moorehead
1998: 60; Palmieri 2012: 1280-1281). The resulting homogeneity of the committee rendered any program or statutes obsolete (Favez 1989: 29). The committee first broke with recruiting traditions in 1918, as it became the first organization of international repute to elect a woman, Renée-Marguerite Cramer, to its governing body-aside from her gender, though, she fulfilled the usual criteria (Favez 1989: 28; Forsythe 2005: 41 and 203; Moorehead 1998: 60 and 260; Palmieri 2012: 1279). Five years later, the first non-Genevan and the first Catholic would follow.

Fast forward to today, and Forsythe's verdict on the assembly's composition still stands: "It remained, and remains, all white" (Forsythe 2005: 41). However, this will hardly surprise anyone familiar with Switzerland's demographics. More importantly, the assembly has stayed mono-national, i.e., all Swiss. While criticism of the leadership's mono-nationality had already been present at the ICRC's founding, former presidents like Cornelio Sommaruga and delegates regarded it as "the only guarantee [...] that the organization will not descend into a UN kind of impotence" (Moorehead 1998: 711). Even though the organization started to diversify its staff in the 1990s, calls for internationalizing the assembly have died down (Forsythe 2005: 207). Aside from mono-nationality being a guarantor for stability and an insulation from international politics, it has generally become less problematic due to an internal power shift. During the 1970s, the leadership role has increasingly moved from the assembly and the presidency to the directorate (Forsythe 2005: 201; Palmieri 2012: 1292) which is nowadays reflective of the ICRC's internationality and gender equality as it currently consists for the first time in the organization's history of more women than men (ICRC 2018a, 2018b).

The assembly tries to be mindful of Switzerland's own diversity, urging in its recruiting policy that "the country's main linguistic regions be represented" (ICRC Assembly 2015: II Collective Criteria), though without suggesting a criterion of fair geographical representation among the Swiss cantons. Consequently, there is still a strong Genevan component in the assembly, but overall greater diversity in terms of gender, professions, and Swiss regional origins represented.

\section{Swiss organizational culture?}

Until the early 1990s, the ICRC was dominated by the Swiss: not only the assembly, but also the majority of its delegates were of Swiss origin. With the possibility of Switzerland joining the European Economic Area (EEA) and the shortage of prospective delegates in the domestic labor market, the organization had to re-consider its mono-national staffing (Forsythe 2005: 230-231). In spite of the (on-going) internationalization of the ICRC, one may still wonder to what extent or in what ways the organization's Swiss roots and history are palpable or visible in 
its organizational culture. Interestingly, few have addressed this question. In a short essay on the relationship between the ICRC and the Swiss state, Gasser only cursorily glances at the issue and perfunctorily observes that:

However, the ICRC's present governing elite are of Swiss nationality, have received their education in Swiss schools and universities and live in a Swiss environment. Is there any reason to believe that the Swiss perception of international problems and Swiss approaches to solving them should be absent in Geneva? That Swiss affinity probably creates links that are much stronger than any outside attempt to influence individual decisions. (Gasser 2003: 122)

Forsythe dedicated more room to the question, yet he had to acknowledge the difficulty in addressing the puzzle at all, as "being Swiss is difficult to translate into definite and precise characteristics" due to "the complexity of Swiss culture" (2005: 237 and 238). This would be the case for any culture, one may add. Nevertheless, Forsythe identified several traits he felt telling of the organization's roots. On the one hand, he sees the ICRC's structure and its relationship with the Red Cross movement at large as a reflection of the Swiss political system: decentralization, the idea of "guiding" rather than "governing" member societies (2005: 25-26), the collegiality of the ICRC's directorate (2005: 225) and governing structures. They are more conducive to careful pondering of subjects rather than to the display of individual ambition and charisma (2005: 223). The latter is accentuated by the way the ICRC "strives for predictability" and thus leaves no room for "officials who exceed agency guidelines or who are not evaluated as sufficiently predictable" (2005: 170). In its relationship with the outside world, Forsythe also sees the ICRC's discretion, bordering secretiveness, as an expression of what sociologist Jean Ziegler decried as Switzerland's "ideology of secrecy" (2005: 14 and 239). Together with historian Michael Ignatieff, though, he also sees the pragmatic outlook of the organization. Rather than being idealistic in its view of war and the possibility to "humanize" warfare, the ICRC-thus Ignatieff-has a "very Swiss" attitude towards war, which is not pacific but that of "armed neutrality" (Ignatieff 2001: 22-23). ${ }^{4}$ While the ICRC condemns armed violence, it keeps a realist outlook on the world and works within the reality of war. Such realism and secrecy are further underlined by a certain "Swiss aloofness" (Forsythe 2005: 91 and 239) or lack of (displayed) effect.

\section{Values: theoretic considerations Definition and framework}

Despite its ubiquity, the meaning of "value" is rather elusive and contingent per se, as the term has different meanings in various disciplines. Generally speaking, values are preferences, stemming from a sense of right and wrong, which have an impact on behavior considered as appropriate in the ethical, ideological, social, or esthetic spheres. In other words: "Values reflect what is important in life. They give meaning to the things we do," as the Research Center for Human and Cultural Values at the University of Western Australia (2017) puts it. Values "vary among individuals and across cultures and time," but "are universally recognized as a driving force in ethical decision-making" (McCombs School of Business 2017). In any context, they develop a prescriptive and a proscriptive force (Jost et al. 2015: 355). Consequently, we conceive values as a dynamic, processual system that is-in contrast to principles and norms (e.g., in an organization)-negotiable. Moreover, values figure as a fundamental ingredient of most definitions of organizational culture and are said to significantly correlate as a tangible factor of the organization's successful performance. They determine vocation commitment, the mission, and desired strategic goals of the organization.

Multiple studies have attempted to provide a framework to analyze and categorize values. Among them, psychologist Shalom H. Schwartz has achieved prominent-or even dominant (Jost et al. 2015: 359)-status with his framework that he structured according to value domains. We appreciate his pioneering approach, and we will take his basic structure as a point of departure to develop our own framework. In order to address some of the shortcomings of Schwartz's approach, we also build on alternative studies and our own findings. In other words, we do not suggest that Schwartz's approach needs to be rejected; he has laid the groundwork for our own value dimensions. However, his categories need to be adapted and modified in light of criticism of his work.

Schwartz draws said framework on his theory of basic human values that he supports by intercultural theories and his earlier research jointly undertaken with Wolfgang Bilsky (Schwartz and Bilsky 1987) which they derived from data collected in seven countries. He defines basic values as "desirable, trans-situational goals, varying in importance" (Schwartz 1994: 21) and divides them into 10-value domains, namely, security, conformity, tradition, benevolence, universalism, self-direction, stimulation, hedonism, achievement, and power, arranged in a quasi-circular structure that indicates the relation between values to each other: the structure indicates whether values are compatible, incompatible, or unrelated to each other (Schwartz 2012). With regard to cultural value orientations, Schwartz also specified three bipolar dimensions (Schwartz 2014: 551552): autonomy vs. embeddedness, egalitarianism vs. hierarchy, and harmony vs. mastery.

Schwartz's framework of universalistic basic values has its merits and has been frequently tested in his own and 
related scholarship. Yet, Schwartz perpetuates the flaws already massively criticized in the popular framework of comparative intercultural research theories, as developed by Geert Hofstede. ${ }^{5}$ The latter keeps up bipolar and essentialist thinking ${ }^{6}$ and generalizations, resulting in a persistence in national stereotypes. For instance, Hofstede transferred specific characteristics of organizational culture of one company to a whole nation, no matter how big and multicultural the nation. Schwartz's universalistic value domains fall into a similar generalization trap. In other words, his approach ignores process dynamics and multiple relations of the domains.

In contrast to Schwartz, other authors have highlighted said dynamism and have addressed the necessity of incorporating them in their research. For instance, Bourne and Jenkins (2013) stress the dynamics of organizational values for any generated values framework: "Organizational values incorporate present ['embedded'] and future ['intended'] orientations, and are both individual and collective structures" (31). Relationships between forms of values are theorized in configurations leading to change time and again. These two authors insist on the "dynamic" and never consistent and uniform construction of their scheme prone to transformation. Similarly, Finegan (2000) recognizes the multidimensionality of values and "that each value cluster may affect behavior differently" distinguishing "affective, normative, and continuance commitment of staff" (149).

Both the multipolar and ever-changing character of a set of values (in an organization) lead us to elaborate a different form for our framework, converting Schwartz's orderly, symmetric cakes into a rhizomatic network. In other words, we rely on the concept of the (botanical) rhizome as conceived by Gilles Deleuze and Felix Guattari in a Thousand Plateaus (Deleuze and Guattari 1987) to apprehend multiple, non-hierarchical, and non-dualist conceptions of knowledge without a specific origin. A rhizomatic constellation of culture reflects a nomadic system of growth and dissemination and transcultural processes, thus resulting in animated, interconnected categories of values and permeable borders between them. Naturally, any rhizomatic network structure or assemblage has to endure the paradox of relying simultaneously on clear categories or nodes as well as on a dissolved order.

Therefore, we also need to rely on different categories of values, while being aware that these cannot be entirely separate and need to be open for interconnections. As a consequence, we amplify Schwartz's spectrum of cultural values and step away from a binary and antagonistic alignment. Instead, we blend various categories in shifting configurations, without following an illusion of clear order. With Schwartz's framework, we share some value categories, but not his universalistic cultural aspiration of value archetypes. We share the multiple interconnections between values, but not his bipolar, symmetric order.
Specifically, we rely on frameworks of our further readings in value research. Among them, the World Values Survey (WVS) is regularly updated and provides certain useful sections, taken from Inglehart et al. (Inglehart and Norris 2003; Inglehart 2004 and Inglehart and Welzel 2005), such as "secular," "emancipative," "cooperative," and "pro-social" values as social capital for "productive" or "protective" purposes. Others build on Rokeach's (1973) distinction between "instrumental" and "terminable values." In this vein, "McCombs School of Business" (2017) discerns a difference between "sacred" values understood as moral imperatives and "intrinsic" as well as instrumental values. The latter distinction will be applied to our own framework, with intrinsic values referring to desirable end-states of existence (e.g., independence or peace) having worth in themselves. These are complemented by instrumental values, which serve as means to an end (e.g., punctuality or precision) as tools towards a desired outcome. We conceive the pair of categories as dialectic instead of dichotomist; in the same vein, the subcategories are not to be understood as contrasting pairs.

The chosen categories of instrumental and intrinsic values hark back to philosopher John Dewey's reaction to Max Weber's opposition between so-called Zweckrationalität and Wertrationalität. By the former, he referred to a "means-end" or instrumental rationality of social action, whereas wertrational describes a belief-oriented rationality due to which individuals are intrinsically motivated. ${ }^{7}$ Dewey conceived the opposition between instrumental and intrinsic values as pointless and the purpose of both the dependency on each other. Instrumental values can lead to intrinsic values or right beliefs, and vice versa. Above all, Dewey stated that intrinsic values were nothing else than a "contaminated" (Tool 1994: 152 pp.) or hidden application of instrumental values (Dewey 1929: 255). ${ }^{8}$

\section{Dimensions of our framework}

Based on our theoretical considerations, our framework is based on three interacting components: a differentiation between a.) intrinsic values and b.) instrumental values as well as on a c.) network structure.

a.) Intrinsic values:

- Extroversion: we conceive this sub-category as the orientation towards the outside world and the value attributed to engaging with the "other." This cluster reflects that the objects of our study (Switzerland and the ICRC) are both characterized by multiculturalism and dependency on international partners.

- Harmony: according to Schwartz, values in this subcategory "emphasize maintaining the status quo, propriety, and restraint of actions or inclinations 
that might disrupt the solidary group or the traditional order in which people are embedded" (Smith et al. 2002, 193). In later works, Schwartz includes harmony in his basic value security (Schwartz 2012: 6). From the point of view of Swiss values, mastery and harmony are not necessarily opposed categories, if we take into consideration the values included in both clusters: efficiency and consensus, for example, could go hand in hand.

- Ethics: values per se could be subsumed under ethics, but in this sub-category, we focus on general moral values and principles that guide people in their communal lives.

- Restraint: this sub-category features values that deemphasize personal, organizational, or national achievements, and are closely related to the dimension of ethics. Schwartz includes restraint under the basic value conformity (Schwartz 2012: 6). We opted for this category as an umbrella for the value of understatement often associated with Switzerland.

- Egalitarianism: drawing from Schwartz's categorization, we understand "egalitarianism" as "the transcendence of selfish interests in favor of voluntary commitment to promoting the welfare of others" (Smith et al. 2002, 193).

- Autonomy: in contrast to Schwartz, we do not distinguish between affective, intellectual, and political autonomy, because we conceive the dichotomic separation of affect and intellect as problematic. ${ }^{9}$

\section{b.) Instrumental values:}

- Mastery: we adapt this category from Schwartz (1999) who therein sees a "cultural emphasis on getting ahead through active self-assertion" (28).

- Control: in contrast to Schwartz (2012: 6), we do not conceive this category as a power value in the sense of exercising influence, directing, ruling, managing, regulating, or checking. Instead, we subsume values such as rigor, thoroughness, risk aversion, and predictability under this category.

- Embeddedness: values in this sub-category are corollary to the intrinsic values related to "harmony" and show how it is achieved, namely, through a conservative attitude.

\section{c.) Network structure}

Following the rhizomatic outset described above, we represent our value dimensions in a network graph rather than in a circular structure as suggested by Schwartz. This is due to the genuinely transcultural setting of the organization we look at as well as due to the complexity of value clusters and the interrelatedness of the gathered values, depicted through some connecting lines between them, both on the intrinsic and the instrumental side. The connecting lines in the networks will be drawn according to the interrelatedness and multipolarity of values and value categories. We will exemplarily show the rhizomatic structure of some values brought up by the interviewed ICRC staff.

\section{Findings \\ The study}

For our study, we conducted and recorded a total of 22 semi-structured interviews with ICRC staff members, i.e., we followed a guideline with different questions, but remained flexible for unplanned topics. In contrast to other comparable studies, including those by Schwartz, we refrained from presenting a fixed catalog of values to our interviewees, and instead let them develop their ideas about Swiss values unprompted. However, we did distinguish three cultural levels, namely, the organizational (ICRC), the national (Switzerland), and the universal culture (archetypes). Individual, regional, national, universal, or archetypal values complement the organizational value systems and mutually shape each other, without always following a clear chronology. Interviewees were asked what values they considered to be "typically" Swiss.

In order to analyze whether Swiss values affect the institutional structure, the organizational culture, and the humanitarian work of the ICRC, interviewees had to comment on whether the values they consider as Swiss were important for the organization as a whole and for their personal work or whether they rather perceived a disconnection from the Swiss context. In particular, we inquired how our respondents viewed the relationship between the Swiss state and the ICRC to further establish to what extent the erstwhile equation between the two still influences the organizational culture and values. During our entire study, we were mindful of three distinct perspectives, which define how values are viewed. In the case of the ICRC, this multipolar orientation encompasses the staff's and organization's self-image, the external perspective or heteroimage, and the meta-image, i.e., how interviewees believe the ICRC to be perceived by others (Beller and Leerssen 2007: xiv and 344). In a final step, we held a workshop with senior staff of the ICRC in order to discuss our findings. Though the sheer number of our interviewees suggests a rather rough sketch of the organization, the joint reflection and feedback project showed that our study hit many a nerve and astutely reflected internal discussions.

Among our 22 respondents, 10 possess the Swiss nationality from birth and were socialized in the Swiss 
education system. Another group of interviewees consists of five persons nationalized after having lived in Switzerland for several years. Seven of our interviewees were non-Swiss. Nine of our respondents were women, 13 of them men. Almost all of our respondents, both international and Swiss, had several years of field experience and now mainly work at headquarters in Geneva. On average, the interviewees had worked for 8 years in the field, and for six and a half years at headquarters in Geneva. The 22 interviewees represent a diversity of educational backgrounds, ranging from medical training, law studies, political science, international and regional studies, history, literature, natural sciences, and economics. In addition, the majority had worked for different organizations before. The respondents currently hold different positions at the ICRC: we interviewed one Swiss member of the directorate and three of the assembly. The positions of the other interviewees range from heading a health, regional, or policy unit to being a first-year associate at the ICRC. Interviews were held during the first half of 2017.

In the discussion of our interviews, we first give a brief overview of the responses by our interviewees, as visualized by our network graphs. We then discuss the general discourse in the ICRC on values that are largely informed by the lack of differentiation between values and principles. In the next step, we analyze the findings in light of the cultural levels, i.e., we first ask to what extent Swiss values permeate the institutional structure and the organizational culture. As the latter is marked by the
ICRC's dual nature, namely, the difference between work at the headquarters and in the field, we then address to what extent interviewees believe values to differ in Geneva from the rest of the organization's operations. Subsequently, we turn to the relationship between the ICRC and the Swiss state which is, finally, affected by the rather recent internationalization of the organization.

\section{Overview: perceptions of Swiss values in general and at the ICRC}

Based on the interviews, we developed the network graphs below, the first showing what values our respondents associate with Switzerland in general and the second one displaying which of these Swiss values are considered important to the ICRC. The values were clustered according to the categories explained above. First, depending on their content and function, the values representing a desirable end-state of existence were assigned to the intrinsic dimension, while the values serving as means to an end were referred to the instrumental dimension. Second, in order to get a more nuanced network, the values were assigned to the sub-categories described above in more detail; the bigger the font, the more often a value was mentioned by interviewees (Fig. 1).

The clustering becomes easier to grasp in light of an example: consider the most prominent dimension in Fig. 2, harmony. The said value dimension comprises those values that, as outlined earlier, emphasize maintaining the status quo, i.e., neutrality, consensus, impartiality, prudence, and an apolitical posture. To make the connection

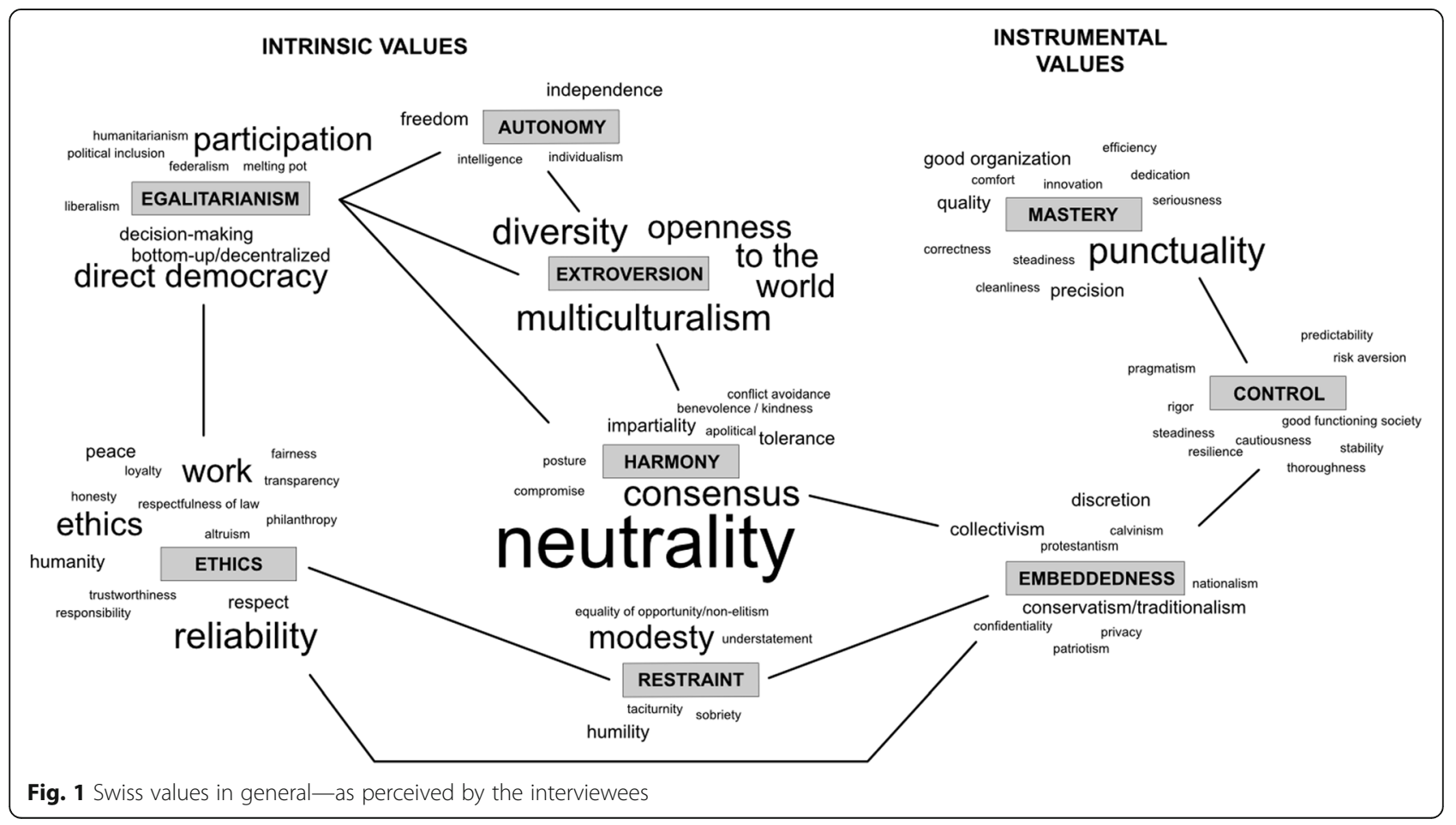




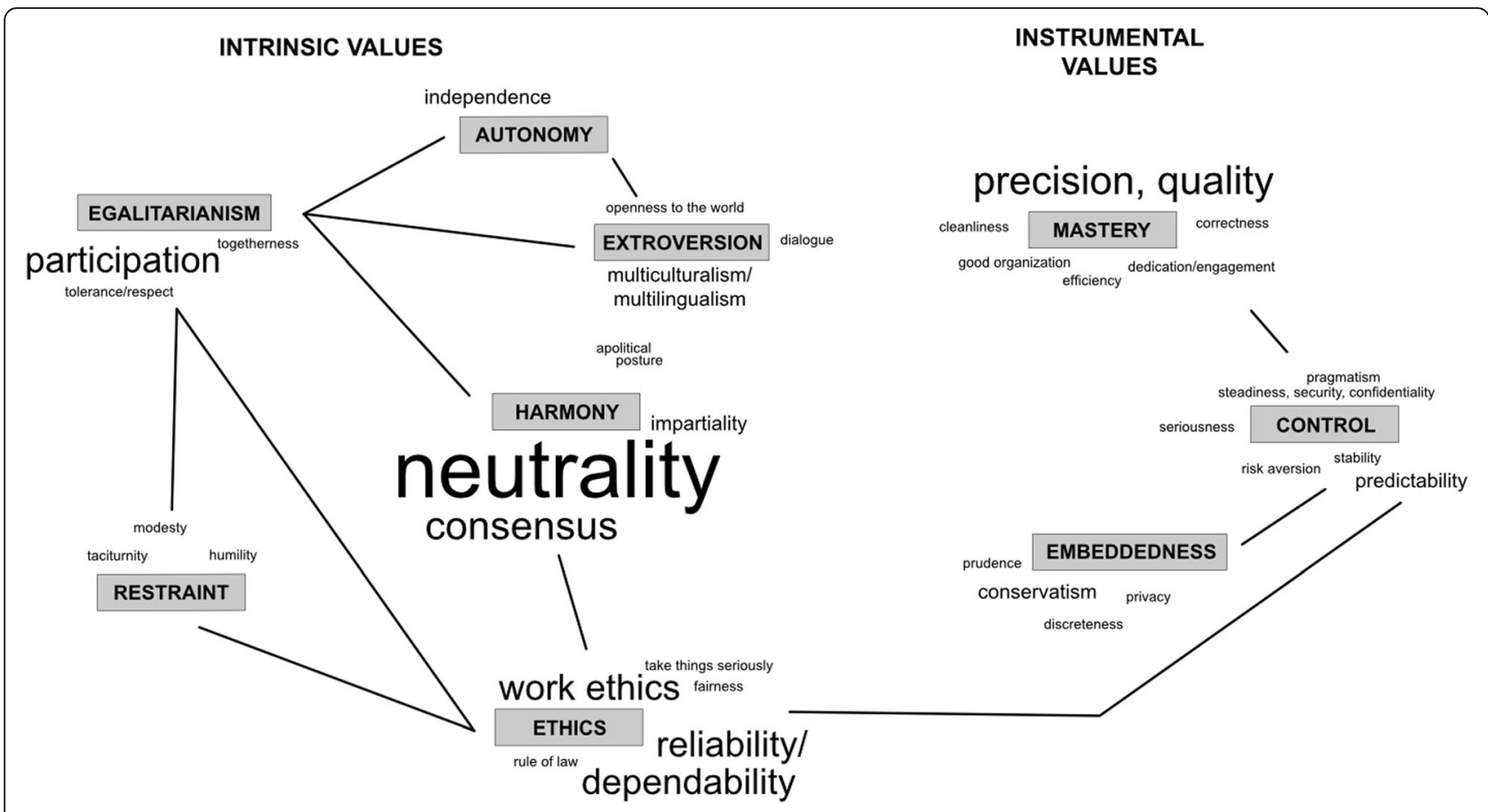

Fig. 2 Swiss values at the ICRC — as perceived by the interviewees

more apparent in the case of neutrality, bear in mind that the latter means the absence of bias and non-intervention in a conflict (Meckled-Garcia 2017), combined with impartiality, thus seeking harmony.

The connecting lines in the networks were drawn according to the interrelatedness and multipolarity of values and value categories. Among the substrate of Swiss values in general, several threads can be traced between and within the two main types of values. The value of punctuality, for instance, connects the categories mastery and control on the instrumental side. Prudence and collectivism, which show cultural embeddedness, also head towards the control dimension with resilience, cautiousness, pragmatism, and risk aversion. The values of cautiousness and prudence are similar in meaning as they allude to a circumspect approach, but the latter adds the connotations of discipline, the use of reason, sagacity, good judgment, whereas the former implies slowness and uncertainty. The restraint cluster may well establish a link to embeddedness through the values of understatement/modesty, on the one side, and prudence/discretion/Protestantism/Calvinism, on the other. There are plenty of connecting lines closing the gap between instrumental and intrinsic values, taking the cluster embeddedness and linking it to restraint (through the pair of values discretion and modesty as one link), harmony (through consensus and collectivism), and ethics (through reliability and discretion). The more you observe the interweaving clusters, the denser the network gets and the more dynamic the value constellations.
To summarize the two graphs, we can make out a few tendencies that will be explored in the context of the institutional structure, the organizational culture, and the tensions between headquarters and field operations.

a.) Intrinsic values:

- Extroversion: contrary to our expectations, several interviewees regard multiculturalism and openness to the world as Swiss values, yet do not underline it as a value at the ICRC. This difference may be due to the fact that extroversion is seen as natural given the ICRC's mission, and that it thus does not require to be articulated explicitly. By contrast, Switzerland's stance on multiculturalism is paradoxical in that it is, on the one hand, a multilingual country with an international hub, Geneva, but it has, on the other hand, chosen a critical distance to European integration. Moreover, this gap in perceptions is interesting once we turn to the relationship between the state and the ICRC as the former highlights its extroversion by making Switzerland's humanitarian tradition-embodied by the Red Cross-part of its national branding strategy.

- Harmony: in remarkable consistency, our interviewees saw both in Swiss culture in general as well as at the ICRC specifically the values of neutrality and consensus as dominant. This is 
reflected in both the general discourse on values and principles as well as in the organizational culture.

- Ethics: similarly to the previous sub-category, work ethics, and reliability are seen as core values on the national and the organizational level and determine the discourse on values in the organizational culture.

- Restraint: while interviewees identify modesty, humility, and taciturnity as present at the ICRC and in Switzerland as such, they see modesty (or understatement) as more of a Swiss than an organizational value. Again, this may be due to the fact that the awareness for the ICRC's culture of modesty is low as it is solidly ingrained. That the heroes and heroines of humanitarianism are not celebrated, that the organization avoids any semblance of ostentatiousness-these characteristics go without saying and are taken for granted. Or to quote members of both the assembly and the directorate: "No heroes, no medals, no statues."

- Egalitarianism: Swiss and non-Swiss interviewees stress the importance of direct democracy and thus participation on the national level; within the ICRC, participation is valued, though differences persist between headquarters and the work on the field.

- Autonomy: as independence is a core principle of the ICRC, it is not surprising that interviewees regard it as an important value relevant both at the national and the organizational level. As is the case with harmony, values in this category tend to be equated with ICRC principles.

b.) Instrumental values:

- Mastery: for our interviewees, Swiss culture is defined by a myriad of values related to mastery, but they perceive punctuality to be dominant. Interestingly, on the organizational level, interviewees stress precision and quality whereof punctuality could be regarded as a consequence or sub-aspect.

- Control: though closely related to the previous division, values in this sub-category, i.e., predictability, pragmatism, or stability, are not dominating on either national or organizational level.

- Embeddedness: while none of the qualities in this category stood out to the interviewees, they agree that they are present both on national and organizational level.

Values-principles-norms

In the context of the ICRC, it is remarkable how the majority of interviewees made no distinction between values influencing the organization-and thus their own work-and the principles derived from these values. In the general discourse at the ICRC, thus a commonly heard opinion, the notion of values is less used and considered as both fraught and problematic. Attempts by the directorate to initiate discussions on shared values failed as staff members considered this less pressing an issue than focusing on the ICRC's mission and principles. Consequently, our interviewees were also quick to equate values ascribed to Switzerland with the ICRC's Fundamental Principles, proclaimed in 1965, which the organization shares with the Red Cross and Red Crescent Movement, namely, humanity, impartiality, neutrality, independence, voluntary service, unity, and universality (ICRC 2009: 9-10), not to be mistaken with "universalism." Calling them interchangeably "principles" or "values," interviewees agreed that these belonged to the "DNA of the organization" or to its "core identity."

The equation between values and principles, as suggested by the interviewees, requires some clarification. One binational interlocutor, the only one to reflect on the difference between principles and values, argued that ICRC principles were "conceptualized," "systematized," or "translated" Swiss values of an organizational culture that have evolved for 150 years and turned into the policy of the institution. Principles are a strong part of the policy for an organization's governance, as they constitute fundamental propositions, essential qualities, requirements, and obligations of a system of behaviors (English Oxford Living Dictionaries 2018), right conduct, or management. Principles as well as norms, understood as specific rules subject to sanctions, can be derived from values and virtues, the latter conceived as values put into practice (Krupansky 2018: n.p.). We thus can construct a triadic ascending line of desirable values, guiding principles, and binding norms for a person, group, organization, or community to determine rightfulness of actions. In other words, principles can take an intermediate position between norms or rules and values.

One example is particularly telling of how interviewees were not perceiving a difference between "values" and "principles": neutrality, part of the intrinsic value cluster of harmony. The Swiss value perceived as most strongly influencing the ICRC and the personal work of the interviewees was said fundamental principle of the organization. Asked about the definition of neutrality, the interviewees quite consistently emphasized that neutrality meant "not taking sides." Some of the interviewees took a more differentiated stance, stressing that the term has a range of meanings. A Swiss interviewee with 17 years of experience as a delegate recalled how (s) he would explain her/his understanding of neutrality in the field: "My definition of neutrality working for the ICRC is not 'not taking sides'. On the contrary, I will take 
sides, but I will take sides of the victims." In a similar manner, several interviewees stressed the idea that neutrality does not mean indifference to human suffering. Accordingly, one binational interviewee followed the standard wording, but added the notion of personal involvement: "[It] is not about being neutral about suffering, it's not that we don't care. It is about helping everybody based on impartiality. Taking sides will hinder your ability to act." Thus, they closely associated the basic principle of neutrality with the supreme goal of the ICRC, i.e., to help victims of armed conflicts. The principle of neutrality therefore may be understood as an essential value per se for the ICRC and its work. ${ }^{10}$

This account corresponds to the perception of neutrality by the Swiss population. According to the annual security survey conducted by the Swiss Federal Institute of Technology (ETH Zurich), neutrality is considered to be of high importance for Switzerland. For 85\% of respondents, neutrality is "inseparable from the Swiss concept of the state" and represents a value in itself. Consequently, support for the principle of neutrality in Switzerland has remained constant over the years and stands at $95 \%$ in 2018 (Szvircsev and Wenger 2018: 52).

Aside from neutrality, two other principles were repeatedly equated with Swiss values in general: independence, part of the autonomy category, and impartiality, strongly associated with neutrality and thus also part of the harmony cluster. For the interviewees, the principle of independence entails the possibility to operate autonomously of any influence nor interests of other actors, including states and international organizations. Impartiality, on the other hand, requires that their work be undertaken on the basis of need and need alone, with no discrimination as to nationality, race, religious beliefs, class, or political opinions. The interviewees acknowledged the Swiss roots of these values and stressed that they would need to be applied throughout the whole organization despite the ongoing process of internationalization. Strict adherence to values and principles, thus, all interviewees agreed, is considered as vital for the ICRC's effectiveness in the long term.

\section{Institutional structure}

Talking about Swiss values still influencing the ICRC, some interviewees stressed that the institutional structure is designed to ensure a system of participation on major policy developments, thus reflecting the Swiss political system and values associated with the category of egalitarianism. The ICRC is headed by the president and the top policy-making body is the assembly. However, the daily operational policy is largely made by the director general and the directorate, consisting of the heads of the five ICRC departments (ICRC 2018a: 43). Thus, the participative institutional structure prevents any organ wielding excessive power in policy and operational decisions; it thus follows the idea of checks and balances. One interviewee commented on the institutional structure as divided, but also of shared competencies between the assembly and the directorate: "I think it makes the job more complex for some of the people at the top, because they really have to manage up and down at the same time."

Considering the most distinctly "Swiss" aspect of the ICRC's institutional structure, all interviewees pointed to the assembly, the supreme governing body that is only open to Swiss nationals. ${ }^{11}$ This built-in Swiss structural core of mono-national leadership was widely perceived as crucial for the organization's independence from international politics, interest groups, and any other entity that may have some connection with a situation of violence. As one Swiss interviewee, who had worked for the ICRC for 22 years, observed: "The ICRC over its history has managed to be protected from political considerations. The very day you open up the Assembly to non-Swiss nationalities, this will be the biggest carpet bargaining like we have in the UN." The interviewee further stressed that the existing governance structure also guarantees that no political considerations are influencing the nomination of the directorate or lower staff levels. In other words, the interviewees perceive the assembly as a guarantor of some of the ICRC's fundamental principles and thus-in the interviewees' diction-its values: independence, neutrality, impartiality, and unity.

\section{Organizational culture}

In addition to formal structures, organizations are characterized by informal rules, norms, and accepted ways of doing things. These are essential constituents of organizational culture. In contrast to the accounts on the ICRC's Fundamental Principles and the institutional structure, assessments to what extent Swiss values still affect the organizational culture vary among the interviewees. The statements may be summarized in a traditional and a skeptical narrative.

The traditional narrative highlights the importance of the institutional history for the organizational culture and stresses that Swiss values are still of high importance even for the organization's day-to-day activities. Interviewees furthering a traditional narrative underlined that the ICRC's organizational culture was shaped by Swiss values, then conceptualized in the organization's fundamental principles and in the mission statement, and thus is slow to change. As examples, interviewees observed that the decision-making process within the ICRC - particularly at headquarters - shows a consensusoriented, pragmatic approach, which tries to take into account all interests involved. This consensus-driven 
culture may have been influenced by Swiss political culture that is often characterized as a "consensus democracy" aiming at a high participation of citizens and thus harmony as well as egalitarian values. A non-Swiss interviewee had worked for 3 years in the human resources department and was involved in a major change management project which made him/her aware of the consequences of such a culture. (S)he observed that the staff expected to be included in the process as intensely as possible: "People really want to participate in discussions. They really want to have a voice." (S)he started to understand this need for consultation after knowing more about Swiss politics with the possibilities of citizens to vote on numerous referenda. This impression of the ICRC consensus-led culture was shared by a nonSwiss interviewee formerly working for the UN and describing the different procedures in light of as simple a task as speech writing. At the UN, "you first draft a speech and then you go through various clearances with your direct supervisor and his or her boss and the next boss et cetera. At the ICRC, you get as many people involved as possible, you discuss it and get all the inputs." Some admitted, however, that this practice-laudable as it may be in its intentions and outcomes-could also be perceived as conservative since it requires a lot of time and the organization thus is persistent or slow to reform its policies. In addition, the focus on consensus may lead to the avoidance of conflicts that may keep simmering internally and remain unresolved.

Reliability and dependability on ICRC policies and, consequently, the consistency of ICRC staff are additional values underlined by those adhering to the traditional narrative, thus pointing at instrumental values in the categories of control and mastery and the intrinsic category of ethics. In the course of conducting interviews for this article, this was clearly evidenced in two particular ways. First, regarding the decision-making within the organization, after a possible scope for internal dissent in the discussion of the proposed policy, once adopted, ICRC staff members consistently support the policy. One interviewee observed that the ICRC could be described as "fierce in consultation but loyal in implementation". Second, a consistent and dependable implementation of ICRC policy is perceived as essential for the work in the field. Nevertheless, it slows down decision-making processes. One interviewee emphasized that it may take years before the ICRC will be able to visit a prison. The staff starting the process will not be in charge of visiting the prison anymore, instead a new colleague assigned to the operation. The ICRC policies however must be consistent across different contexts and even when staff is rotating. (S)he concluded with understatement, pointing to the category of restraint: "You are not a hero. You are just one among a lot of people."
The skeptical narrative-furthered by some Swiss interviewees-recognizes a certain influence of Swiss values on the present organizational culture, yet the skeptics doubt if all ICRC staff members interpret these values in the same way. Values commonly perceived as Swiss may be injected into non-Swiss staff members, but the understanding of the concepts and Weltanschauung behind the values may differ. As an example, one Swiss interviewee observed that foreign colleagues may of course accept the principle of neutrality but interpret it not as a value as such rather than as a means or a precondition for the ICRC to get access and to speak with every belligerent. (S) he concluded that for non-Swiss staff, neutrality "is more an application of a concept than a real concept." This attitude stands in contrast to the situation before the ICRC's internationalization when only Swiss citizens were working as delegates who were more conscious of neutrality as a value per se.

Though traditionalists and skeptics may disagree on the importance of Swiss values in the ICRC today, yet they agree on the positive impact they once had on the organization in its entirety. In this vein, one Swiss interviewee with over 16 years of field experience stated that (s)he would "like to retain Swiss values at the ICRC, without having more Swiss staff." A non-Swiss interviewee for her/his part stressed his/her satisfaction about working for the ICRC: "The ICRC is the best and the essence of Switzerland-the best of Swiss values is concentrated at the ICRC." As one Swiss interviewee with over 20 years of ICRC experience observed, the attitudes and socialization of the staff members are extremely important to preserve the organizational culture which (s) he considered as a success factor for the ICRC: "Once we become like any other organization, we will be treated like any other organization."

\section{ICRC headquarters and field operations}

At the time of our interviews, the majority of interlocutors was working at ICRC headquarters in Geneva, but they had several years of field experience. Although most of them did not make a distinction between the impact of Swiss values on the work in the field and at headquarters, some characteristics shone through. The work of the ICRC follows a "dual nature," along two distinct, yet interconnected avenues (ICRC 2009: 6). The first "operational" one focuses on the help for victims of armed conflict and other situations of violence in the field. The second involves developing and promoting international humanitarian law and humanitarian principles. However, the dual nature of the ICRC's work comprises the headquarters in Geneva and delegations and missions in more than 80 countries around the world. It is at the headquarters where the assembly as governing body and the directorate as executive body of the ICRC work and formulate general 
policies. In 2017, 1016 people were employed at headquarters (ICRC 2018a: 82), supporting field operations, strengthening the ICRC's role of advocate and defender of international humanitarian law, and dealing with governments and with partners in the humanitarian community. Headquarters also manages financial issues and logistics as well as human resources. With its department of operations, ICRC headquarters maintains a close link to its broad network of delegations with 15,570 employees in the field (ICRC 2018a: 82). In spite of these close ties, though, the different work environments affect the values upheld by employees.

In this vein, two of the interviewees perceived the work culture at headquarters as more hierarchical than in the field, i.e., they felt that values related to control and embeddedness are more dominant at headquarters. They further observed that this hierarchical structure reflected the use of military terms for internal functions and processes. Some meetings, for example, still receive the name of étatmajeur. Although delegations in the field also display a hierarchic structure, they could nevertheless be described as more bottom-up in their work approach, thus stressing egalitarianism even more than at headquarters. Delegates in the field strive for substantial decentralization and express non-hierarchical needs or a dose of independence from headquarters in order to preserve their requirements of dynamism and spontaneity. In addition, although ICRC headquarters wants everyone to follow a consistent general policy, it often defers to delegates in the field and gives them considerable freedom of action. This allows for a certain degree of innovation in terms of how to address challenges of armed conflicts or other situations of violence and seek a pragmatic solution, albeit within the strict boundaries of the non-negotiable institutional principles. In essence, Swiss values such as innovation, pragmatism, and participation are important assets in the field.

By contrast, the processes at headquarters to formulate or change general policies are perceived as slow-paced. The interviewees considered this institutional persistence as a consequence of the conservative, consensus-led internal decision-making processes of the organization. The formulation or reform of policies at headquarters may require a lot of patience, as they are guided by Swiss values such as stability, predictability, conservatism, and consensus. These are considered vital for the organization's success, credibility, and legitimacy. They may be at loggerheads with the preferences of those working in the field, but, some interviewees argue, both logic and value-sets are interdependent and complete the ICRC as an organization.

\section{Relations with the Swiss state}

With a focus on Swiss values comes the question as to how the ICRC collaborates with and sets itself apart from the state that is allegedly home to the said values. The interviewees are well aware of the historically close ties with the Swiss state, their disastrous influences on the ICRC's work in the past, and the resulting major difficulties for the organization's independence. However, they agreed that during the last few decades, the close relationship with the Swiss state loosened, in particular with the Headquarters Agreement of 1993 guaranteeing the ICRC absolute independence and freedom of action, both essential for the ICRC to operate in accordance with its fundamental principles. Regarding the present relations of the ICRC with the Swiss state, the staff member's narratives are very consistent in that they appreciate the stability granted by the Swiss state, but most are aware of its drawbacks. Fittingly, an interviewee called the close relationship both "a blessing and a curse."

Regarding the positive aspects of the relations of the ICRC with the Swiss state, two major areas of cooperation came up. Firstly, the interviewees agreed that the relations with Switzerland in financial matters are extremely important and vital for the organization's operations. Switzerland as one of the major donors has proved to be a reliable partner for funding the ICRC's headquarters' budget as well as for various field operations. ${ }^{12}$ Against this background, the interviewees assessed the relations with the Swiss state in financial matters as very positive and beneficial for the ICRC's operational capacity. In a sense, the Swiss state contributes to the ICRC's ability to maintain its core values of independence and neutrality.

Secondly, the interviewees appreciated Switzerland as a partner on the international level to implement legal initiatives aimed at strengthening compliance with international humanitarian law and improving humanitarian access. The support of Switzerland as depositary state of the Geneva Conventions encourages other states to contribute to the development of additional instruments in the field of international humanitarian law. In this respect, the interviewees consider Swiss foreign policy as beneficial and not creating difficulties for the ICRC or its independence. For their work in the field, the interviewees did not perceive any significant negative effects resulting from the relations of the ICRC with the Swiss state.

However, Swiss politics may at times raise concerns and affect the way the ICRC is perceived. After the Swiss people and cantons agreed to adopt a popular initiative amending the constitution to prohibit the construction of minarets in Switzerland in November 2009, the interviewees saw the image of Switzerland suffering, above all among Muslim communities. As 6 out of the 10 largest operations in 2009 in terms of expenditure were in mostly Muslim countries (Iraq, Sudan, Pakistan, Afghanistan, Somalia, and Chad), ICRC headquarters was worried about the effectiveness of the respective operations. ${ }^{13}$ In this context, it helped that the ICRC's logo references the location of its headquarters, Geneva, instead of its national roots, Switzerland. However, 
the organization did not experience concrete problems on the working level because of the acceptance of the initiative by the Swiss people and cantons. In sum, the ICRC's operations have hardly been compromised by political decisions of Switzerland. The interviewees explained this fact with reference to the perception of the ICRC in the field as being more and more an international, not a Swiss organization. In the same vein, the ICRC President, Peter Maurer, acknowledged that Swiss political decisions affected the ICRC not directly. Nevertheless, he wished for a clear humanitarian profile of the Swiss state-even in questions such as arms exports and prohibition of nuclear weapons-in order to have a credible partner in promoting ICRC initiatives (SRF 2018, September 1).

Related to this issue, three Swiss interviewees observed that Switzerland tends to highlight its close link to the ICRC in order to promote its own foreign policy. The Swiss government may use the ICRC as an example and instrument of its own humanitarian efforts on international level and make it part of its branded "Swissness." Nation branding is understood as "the unique, multidimensional blend of elements that provide the nation with culturally grounded differentiation and relevance for all of its target audiences" (Dinnie 2008: 15). Thereby, governments aspire to create a "favorable perception, be it with regard to exports, governance, tourism, investment and immigration, culture and heritage, or people" (Sevin et al. 2018) according to marketing and branding paradigms. The Swiss state has even created an organization, Presence Switzerland, that is responsible for the promotion of the image of the Swiss state abroad, for implementing the communication strategy of the Federal Council, and transmitting a portrayal of the country's diversity and attractiveness. It is not surprising that Switzerland's humanitarian tradition also features in these attempts at marketing the country, with the ICRC being seen as an asset. While such branded "Swissness" may be beneficial for export industries and service sectors, it is of lesser interest to an organization like the ICRC. The ICRC may want to project its values, yet it does not want to see them associated with the ostentatious tackiness and stereotyped narrowness of branded identities.

The ICRC thus must strive to clearly define the scope of cooperation in order not to be perceived as an extension and means of instrumentalization of the Swiss government, as it once had been in the past. This may become less likely the more international the ICRC gets. Yet, this is a fine line to walk, as one interviewee observed, since "one day, Switzerland will have to decide whether the ICRC is still as important to the country as an international organization as it was as a Swiss organization."

Finally, the one link between the ICRC and the Swiss state, which was mentioned as problematic by almost all interviewees is the fact that there seems to be a revolving door between the top levels of the Swiss government and the ICRC's presidency. The three most recent presidents of the ICRC were former high-ranking Swiss diplomats. This seemingly continuing practice may raise questions about the ICRC's true autonomy and its independence not only from the Swiss state on an international level, but also within the Red Cross Movement. Indeed, on an international level, it may be unclear if the president represents the ICRC's mandate or the position of Switzerland which he once had to represent as a diplomat. In addition, an interviewee who had worked on the relations of the ICRC and the Red Cross national societies, pointed out constant questions from boards of national societies about the ICRC's independence from Swiss authorities, even raising doubts whether the ICRC "practices what it preaches." Although the interviewees agreed that former diplomats and members of the federal administration may have a large carnet d'adresses, which is beneficial for the ICRC, some wondered about the reasons for this continuing practice and whether it is open to change. Continuity is valued, yet it does not go unquestioned.

\section{Effects of internationalization}

The ICRC has undergone a process of professionalization and internationalization that has affected not only staff statistics but also the organizational culture. Assessments to what extent these developments have been beneficial or detrimental to the ICRC and the perpetuation of its values vary among the interviewees. We can distinguish three narratives, namely, an internationalist, a traditionalist, and a pragmatist one.

An internationalist narrative is furthered exclusively by non-Swiss staff members, who perceive the ICRC's internationalization as a necessity and a positive development. While they appreciate the Swiss roots of the organization and the importance of Switzerland as the ICRC's home, they do not witness any negative effects for their work in the field due to an increasingly internationalized staff. Instead, they regard the ICRC's mandate and key principles as the main guarantor of their work's acceptance and legitimacy-a factor that may, as some concede, be supported by the organization's ties to the Swiss state, but not supplanted by them. However, most stop short of applying an internationalist agenda to the ICRC's leadership. With only one exception, all interviewees agreed that the ICRC's board should remain exclusively Swiss to shield it from the type of conflicts that might ensue if a geopolitical quota had to be applied. Some admitted that prior to their work at the ICRC's headquarters, they may have questioned the benefits of a mono-national board, but the insights into political tensions affecting other organizations demonstrated that mono-nationality ascertained independence. Finally, believing an internationalist narrative is not equal with 
unawareness of the ICRC's evolution. Several have observed the changes in the ICRC's use of languages, with English becoming increasingly dominant. While French served as the internal lingua franca in the past, it is nowadays more common to accommodate those only fluent in English. Internationalists see this as a natural consequence of the organization's evolution, though some are still puzzled by the transition.

In contrast to the internationalist narrative, traditionalism is shared by Swiss staff members with ample field experience who are concerned that the internationalization and professionalization of the ICRC is moving the organization in the wrong direction. One Swiss interviewee observed that the ICRC was more and more "feeling like the UN," a development that (s)he considered detrimental to the organization. Another Swiss interviewee with 17 years of field experience corroborated this view, claiming that "it is extremely trendy to be an international rather than a Swiss organization." Part of the trend is the linguistic shift, a trend that traditionalists criticize and find even alienating to a degree: the loss of a language also constitutes a shift in feelings of belonging. While they acknowledged the difficulties in recruiting a sufficient number of Swiss staff members with the required skillset, ${ }^{14}$ this group of skeptical traditionalists regarded a Swiss passport as an asset in their work on the field and bemoan that Swiss candidates are hardly ever given preference. In light of the increasing polarization in world politics that rendered it impossible to employ and deploy people of certain nationalities, ${ }^{15}$ being Swiss still conveyed the message of neutrality beyond the ICRC's organizational culture. As one Swiss interviewee remarked: "I was neutral, because I was Swiss-not because I was with the ICRC." By contrast, the same interlocutor observed, staff members of other nationalities may be confronted with stereotypes and be reduced to their ethnicity rather than being primarily perceived as ICRC members. Referring to his field experience, (s)he explained: "African representatives were telling me that, in the past, they were honored to receive Swiss delegates. Now they are displeased that we are trying to help them with their neighbors."

The pragmatist narrative, shared by another group of Swiss staff members with considerable experience, recognizes the benefits stemming from a more mono-national staff, yet highlights the shortcomings given the changed humanitarian terrain. As an interviewee puts it, (s)he also enjoyed "the good old days" when they would play cards in the field and rant about their military service in Switzerland, but that the current demands on the ICRC's operations left little room for another option but internationalization and professionalization. Pragmatists, in a somewhat ambivalent attitude, hope for the Swiss core to remain strong, yet they support the ICRC's internationalization. For them, the ICRC's principles carry more weight than a Swiss passport.

\section{Conclusion}

"I am not swimming in a bath of Swissness," one interviewee cheekily remarked. While (s)he, in unison with many other non-Swiss staff members, had given little thought to the importance of Swiss values in the ICRC prior to our conversation, (s)he showed astounding clarity in what constituted the core principles and values of the ICRC. An unshakeable belief in these principles, their importance for the vitality of the organization and the operations in the field united all interview partners. That these principles coincided with what many non-Swiss interviewees perceive to be key Swiss qualities only constituted an after-thought for them. Yes, the ICRC may have strong Swiss roots; yes, it may still be under Swiss leadership and relying on the loyalty of the Swiss state-but the organization's heartbeat has become increasingly international. In other words, for international staff, the values of the ICRC have transcended notions of national values and created a more universal organizational culture that does not depend on strong roots and has led to a detachment from the national context. Although non-Swiss interviewees acknowledged the ICRC's historic Swiss rootedness and that the organization's principles reflected national values, they showed less insight into the nature of said Swiss values. As a consequence, none of them bemoans what some of their Swiss counterparts perceive as a loss of Swiss specificity within the ICRC-being themselves part of the wave of internationalization, international staff are accepting and even welcoming the changes. For them, the question of past roots is less pressing than visions for the future. The debate on Swissness is part of said history; the future, by contrast, should be shaped by the question as to how the organization can transcend its Western image and move towards an even more global culture.

One would have expected Swiss interviewees to be less aware of the ways Swiss culture and values have shaped the ICRC, as we tend to have the least insight into what is closest to us. To our surprise, nearly all of our Swiss interlocutors were astutely aware of the way national values had shaped the institution, and how the internationalization was impacting organizational culture. The entirety of the ICRC is confronted daily with the dilemmas of their work and the challenges resulting from the organization's contradictory nature. Yet, it seems to be mostly the Swiss members who consciously tackle those dilemmas resulting from the tensions between the ICRC's Swiss rootedness and its increasingly international culture. In particular, several Swiss interviewees expressed concern that the drive towards internationalization and the adaptation to practices previously associated with organizations like the UN may 
result in a loss of specificity. They regard said specificity closely linked to the ICRC's Swiss core, and fear that a breach with these values may jeopardize their work, but also result in political repercussions. Keeping the Assembly Swiss is therefore not only an insurance against becoming a geopolitical pawn and object of disputes, but it may also guard the ICRC against being uprooted.

At the end of the day, all interviewees agree that what counts is that their work in the field is assured by sticking to the ICRC's key principles, by staying true to their mission, and thus gain access to those in need. Or as a member of the assembly would put it: "The ICRC values are much more important: total commitment, real impartiality, total approach to the culture at the place where you work. You search for the closest connection with the context. There is no other choice. One does not care about Swiss values." Fortunately, fears that Swiss national politics would prove to be detrimental in the field turned out to be premature-the difference between the red and the white cross is well anchored in the stakeholders' minds. Keeping these flags separate will remain important for the ICRC's future-yet it should also nurse its Swiss roots. This does not mean that the answer to "who are we?" should be a resounding: "Swiss!" But it does require being mindful of what the stakes may be if the embeddedness in Swiss culture and history becomes completely irrelevant and the ICRC turns into yet another uprooted international organization.

\section{Endnotes}

${ }^{1}$ Similarly, Kapila (2014: 179) comments that the ICRC embodies several paradoxes.

${ }^{2}$ On this point, several opinions exist. Federal Councilor Schneider-Ammann's viewpoint is reflected in Art. 18 of the Convention for the Amelioration of the Condition of the Wounded and Sick in Armies in the Field, adopted in 1906: "Out of respect to Switzerland the heraldic emblem of the red cross on a white ground, formed by the reversal of the federal colors, is continued as the emblem and distinctive sign of the sanitary service of armies." Aside from Hutchinson, former ICRC historian Pierre Boissier likewise found that the emblem had originally not been chosen to honor the Swiss Confederation (see Bugnion 1989: np.).

${ }^{3}$ According to Jean-Claude Favez (1989: 18), the ICRC first discussed the existence of concentration camps in 1933.

${ }^{4}$ Our own translation from German: "Die Haltung der Organization gegenüber dem Phänomen Krieg ist sehr schweizerisch. Obwohl die Schweiz seit fast zweihundert Jahren Frieden im eigenen Land und seine Neutralität bewahrt hat, ist sie kein pazifistischer Staat. Die offizielle Doktrin lautet: bewaffnete Neutralität. [...] Es besteht eine merkwürdige Parallele zwischen der Kultur des IKRK und der militärischen Kultur" (Ignatieff 2001: 22-23).

${ }^{5}$ Among the many critics of Hofstede's research based on cultural dimensions, Brendan McSweeney (2002: 89-118) might serve as a prominent representative. Shalom H. Schwartz's framework was also criticized as nation-based and essentialist, i.e., by Nathan (2015: 101-124). The stableness of universal values "derived from the basic human conditions" was questioned by several authors (Koivula 2008: 24 or Perrinjaquet et al. 2007; GonzálezRodríguez et al. 2014), as they "may change over time," above all "in response to major technological, economic, political events." (Koivula 2008: 24), as Schwartz himself had admitted. Furthermore, Ali et al. (2008) criticized the predefined cultural archetypes as difficult to uphold due to changes through the recent development and use of information and communications technologies.

${ }^{6}$ Similarly, the Competing Values Framework (CVF) to assess cultural dynamics and possible strategies and standardization of organizational processes relies on four bipolarly arranged "culture-archetypes": internal focus and integration vs. external focus and differentiation on the one hand and, on the other, flexibility and discretion vs. stability and control (Cameron and Quinn 2006: 34-36).

${ }^{7}$ In addition, Weber also distinguishes between affectual and traditional rationality. See also Kalberg (1980: 1145-1179).

${ }^{8}$ See also the Olson (2015: 44-49) and RonnowRasmussen (2015: 29-43).

${ }^{9}$ Moreover, the construction of these sub-groups yields further random categories. Schwartz assigns four values to intellectual autonomy: freedom, creativity, broadmindedness, and curiosity; and another five to affective autonomy: pleasure, exciting lifestyle, varied lifestyle, life enjoyment, and self-indulgence (Schwartz 1992). While autonomy was one of the original seven cultural dimensions in Schwartz's theory, in his later works (Schwartz 2012: 5), he includes the sub-categories of independence, autonomy, and freedom in his basic value of self-direction.

${ }^{10}$ Interestingly, the understanding of neutrality may even differ in the Red Cross Movement. A non-Swiss interlocutor compared the handling of the principle at ICRC headquarters with the one at a National Red Cross Society, for which (s)he worked before coming to Geneva: There, staff was "not that vocal about it," thus neutrality was not given the same explicit importance as at the ICRC in Geneva.

${ }^{11}$ Some interviewees specified that the members of the assembly used to have very close ties to Geneva. According to an assembly member, the city's society has considered the ICRC an emanation of Geneva for a long time, and "the myth persists that it still is a Genevan organization". Nowadays, however, the board is no longer Geneva-centered. 
Nevertheless, "French remains the basic language in the assembly".

${ }^{12}$ In 2017, for example, Switzerland's contribution to the headquarters budget amounted to 80,448,743 Swiss francs (CHF), which was about $54 \%$ of the total funds for the headquarters (CHF 140,881,621). Regarding the budget for field operations, Switzerland's contribution was CHF $69,462,313$, which amounts to about $5 \%$ of the total sum of CHF 1,353,456, 247 contributed by governments (ICRC 2018a: 547). In an interesting side-note, although acknowledging the stable financial support of Switzerland, the ICRC president and the director general recently stated that Swiss authorities could do more to fund and support ICRC's activities (SRF 2018, September 1; Daccord 2018, July 24).

${ }^{13}$ For a comprehensive list of operations in 2009, see the Annual Report (ICRC 2010: 91). In 2017, the operations in Iraq, South Sudan, Afghanistan, and Somalia were still in the list of the 10 largest operations (ICRC 2018a: 82).

${ }^{14}$ Swiss are a minority among newly recruited staff members. According to a member of the assembly, this is has mainly two reasons: (a) the organization grows so fast that one cannot find enough Swiss candidates; and (b) the demand of a profile with a certain skill-set, e.g., being proficient in Arabic, cannot be covered. As (s)he explained: "Growth and profile in demand overshadow the historical element."

${ }^{15}$ Certain nationalities are excluded from serving the ICRC in Muslim contexts. For instance, Danish and US citizens are not deployed into predominantly Muslim countries due to their likelihood of being antagonized and even kidnapped. While US citizens are excluded from service abroad due to their country's military involvement and politics, Danish citizens became targets as a result of the publication of Mohammed caricatures in Jyllands-Posten in 2005.

\section{Acknowledgements}

We are indebted to the ICRC's leadership for opening its doors for our research project. Above all, we would like to thank Dr. h.c. Yves Daccord for his unwavering support and his readiness to establish contacts with members of different ranks. Our interviewees have been generous in sharing their time and insight-many thanks to all of them. This paper was written in the context of the multidisciplinary research project Transcultural Workspaces at the University of St. Gallen and has thus received generous funding from the university's presidency. We are also indebted to the anonymous reviewers for their suggestions that have helped us improve the paper considerably. Finally, we are grateful for Andrea Güpfert's and Alexander Griesser's assistance, particularly in designing the graphs.

\section{Authors' contributions}

The three authors have contributed equally to the research and write-up of this article. All authors read and approved the final manuscript.

\section{Funding}

The research has been funded by the University of St. Gallen, Switzerland.
Availability of data and materials

Not applicable.

\section{Competing interests}

The authors declare that they have no competing interests.

\section{Author details}

${ }^{1}$ School of Economics and Political Science (SEPS) and School of Humanities and Social Sciences (SHSS), University of St. Gallen, Müller-Friedbergstrasse 6/ 8, 9000 St. Gallen, Switzerland. ²Law School, University of St. Gallen, Bodanstrasse 8, 9000 St. Gallen, Switzerland. ${ }^{3}$ School of Humanities and Social Sciences (SHSS), University of St. Gallen, Müller-Friedbergstrasse 6/8, 9000 St. Gallen, Switzerland.

Received: 7 December 2018 Accepted: 18 June 2019

Published online: 09 July 2019

\section{References}

Ali M, AlShawi S, Brooks L (2008) Culture and IS: a criticism of predefined cultural archetypes studies. Conference Paper at Proceedings of the Fourteenth Americas Conference on Information Systems, Toronto, ON, Canada August 14-17, 1-11. https://www.researchgate.net/publication/220891481_Culture and_IS_A_Criticism_of_Predefined_Cultural_Archetypes_Studies. Accessed 25 June 2019

Beller M, Leerssen J (eds) (2007) Imagology: The cultural construction and literary representation of national characters-a critical survey. Series Studia Imagologica, vol. 13. Rodopi, Amsterdam and New York

Bender P (1991) 125th anniversary of the Swiss red cross (1866-1991): thoughts on past and future. Int Rev Red Cross 31(283):359-370. https://doi.org/10, $1017 / 50020860400023603$

Bourne H, Jenkins M (2013) Organizational values: a dynamic perspective. Organ Stud 34(4):495-514

Bugnion F (1989) The red cross and red crescent emblems*. https://www.icrc org/eng/resources/documents/article/other/57jmb8.htm. Accessed 25 June 2019.

Cameron KS, Quinn RE (2006) Diagnosing and changing organizational culture. Addison-Wesley, Massachusetts [Revised edition from 1999]

Center for Human and Cultural Values at the University of Western Australia (2017). Values. http://whatdowevalue.com.au/values/ . Accessed 25 June 2019.

Daccord Y (2018) Les attentes envers le CICR ont changé. Le Temps. https:// www.letemps.ch/monde/yves-daccord-attentes-envers-cicr-ont-change . Accessed 25 June 2019

Deleuze G, Guattari F (1987) A Thousand Plateaus (translated by Brian Massumi). University of Minnesota Press, Minneapolis

Dewey J (1929) The quest for certainty a study of the relation of knowledge and action (Gifford lectures). Putnam, New York

Dinnie K (2008) Nation branding: concepts, issues, practice. ButterworthHeinemann, Oxford

English Oxford Living Dictionaries, s.v. principles (2018) Oxford: Oxford University Press. https://en.oxforddictionaries.com/definition/principle. Accessed 25 June 2019.

Fanzun JA (2003) Swiss human rights policy: between humanitarian tradition and political reluctance. ETH, Zürich

Favez J-C (1989) Das Internationale Rote Kreuz und das Dritte Reich: war der Holocaust aufzuhalten? Bertelsmann, München

FDFA (2016) Swiss Foreign Policy Strategy 2016-19. https://www.eda.admin.ch/ dam/eda/en/documents/publications/SchweizerischeAussenpolitik/ Aussenpolitische-Strategie_EN.pdf. Accessed 25 June 2019.

Finegan JE (2000) The impact of person and organizational values on organizational commitment. J Occup Organ Psychol 73:149-169

Forsythe DP (2005) The humanitarians: the International Committee of the Red Cross. Cambridge University Press, Cambridge

Gasser HP (2003) The International Committee of the Red Cross and its development since 1945. Swiss Foreign Policy:1945, 105-2002, 126. https:// doi.org/10.1057/9780230500242_5

González-Rodríguez MR, Díaz-Fernández MC, Simonetti B (2014) Values and corporate social initiative: an approach through Schwartz theory. International Journal of Business and Society 15(1):19-48

Hutchinson JF (1996) Champions of charity: war and the rise of the Red Cross. Westview Press, Boulder and Oxford 
ICRC (2009) The ICRC. Its mission and work. ICRC, Geneva

ICRC (2010). Annual Report 2009. https://www.icrc.org/en/doc/resources/ documents/annual-report/icrc-annual-report-2009.htm . Accessed 25 June 2019.

ICRC (2018a). Annual Report 2017. https://www.icrc.org/en/document/annualreport-2017. Accessed 25 June 2019.

ICRC (2018b). Directorate. https://www.icrc.org/en/document/icrc-directorate Accessed 25 June 2019.

ICRC Assembly (2015). Policy for recruiting members of International Committe of the Red Cross. https://www.icrc.org/sites/default/files/topic/file_plus_list/ policy_for_recruiting_members_of_icrc_18_june_2015.pdf . Accessed 25 June 2019.

Ignatieff M (2001) Die Ehre des Kriegers. H. M. Enzensberger (Ed.), Krieger ohne Waffen: Das Internationale Komitee vom Roten Kreuz. Frankfurt a. M.: Eichborn Verlag, pp. 9-26

Inglehart R (2004) Human Beliefs and Values: a cross-cultural sourcebook based on the 1999-2002 values surveys. Siglo XXI, Mexico City

Inglehart R, Norris P (2003) Rising tide: gender equality and cultural change around the world. Cambridge University Press, Cambridge

Inglehart R, Welzel C (2005) Modernization, cultural change, and democracy: the human development sequence. Cambridge University Press, Cambridge

Jost JT, Basevich E, Dickson ES, Noorbaloochi S (2015) The place of values in a world of politics: personality, motivation, and ideology. In: Brosch T, Sander D (eds) Handbook of Value: Perspectives from Economics, Neuroscience, Philosophy, Psychology and Sociology. Oxford University Press, Oxford, pp 351-372. https://doi.org/10.1093/acprof:oso/9780198716600.003.0017

Kalberg S (1980) Max Weber's types of rationality: cornerstones for the analysis of rationalization processes in history. Am J Sociol 85(1):1145-1179

Kapila M (2014) The Red Cross and the Red Crescent. In: Mac Ginty R, Peterson $\mathrm{JH}$ (eds) The Routledge companion to Humanitarian Action. Routledge, London/New York, pp 179-190

Koivula N (2008) Basic human values in the workplace. Social Psychological Studies 17:1-141

Krupansky J (2018) Relationship between values and virtues. https://medium. com/@jackkrupansky/relationship-between-virtues-and-values-5f6b90861165. Accessed 25 June 2019.

McCombs School of Business, University of Texas (2017). Ethics Unwrapped. https://ethicsunwrapped.utexas.edu/glossary/values. Accessed 25 June 2019.

McSweeney B (2002) Hofstede's identification of national cultural differences and their consequences: a triumph of faith-a failure of analysis. Human Relations 55(1):89-118

Meckled-Garcia S (2017) On the object and scope of neutrality: policies, principles, and 'burdens of conscience'. In: Laborde C, Bardon A (eds) Religion in Liberal Political Philosophy. Oxford University Press, Oxford https://www.oxfordscholarship.com/view/10.1093/oso/9780198794394.001. 0001/oso-9780198794394-chapter-11. Accessed 25 June 2019.

Moorehead C (1998) Dunant's dream: war, Switzerland and the history of the red cross. Harper Collins Publishers, London

Nathan G (2015) A non-essentialist model of culture: implications of identity, agency and structure within multinational/multicultural organizations. Int J Cross-cult Manag 15(1):101-124

Olson J (2015) Doubts about intrinsic value. In: Hisrose I, Olson J (eds) Oxford handbook of value theory. Oxford University Press, Oxford, pp 44-59.

Palmieri D (2012) An institution standing the test of time? A review of 150 years of the history of the International Committee of the Red Cross. International Review of the Red Cross 94(888):1273-1298. https://doi.org/10.1017/ \$1816383113000039

Perrinjaquet A, Furrer O, Usunier J-C, Cestre G, Valette-Florence P (2007) A test of the quasi-circumplex structure of human values. J Res Pers 41:820-840

Presence Switzerland (2019) Strategie Landeskommunikation 2016-2019. https:// www.eda.admin.ch/dam/eda/en/documents/das-eda/landeskommunikation/ strategie-landeskommunikation-2016-2019_EN.pdf. Accessed 25 June 2019.

Rokeach M (1973) The nature of human values. Free Press, New York

Rona G (2004) The ICRC's status: in a class of its own. ICRC. https://www.icrc.org/ eng/resources/documents/misc/5w9fjy.htm. Accessed 25 June 2019.

Ronnow-Rasmussen T (2015). Intrinsic and extrinsic value) In: Hisrose I, Olson J (eds) Oxford handbook of value theory. Oxford University Press, Oxford, pp 29-43

Schneider-Ammann J (2016) Das Rote Kreuz steht für unsere Werte. Kommunikationsdienst GS-WBF, Bern. https://www.admin.ch/gov/de/start/ dokumentation/reden/reden-der-bundesraete.msg-id-62391.html . Accessed 25 June 2019.

Schwartz SH (1992) Universals in the content and structure of values: theoretical advances and empirical tests in 20 countries. Adv Exp Soc Psychol 25:1-65. https://doi.org/10.1016/S0065-2601(08)60281-6

Schwartz SH (1994) Are there universal aspects in the structure and contents of human values? J Soc Issues 50(4):19-45. https://doi.org/10.1111/j.1540-4560. 1994.tb01196.x

Schwartz SH (1999) A theory of cultural values and some implications for work. Applied Psychology: An International Review 48(1):23-47. https://doi.org/10 1111/j.1464-0597.1999.tb00047.x

Schwartz SH (2012) An overview of the Schwartz theory of basic values. Online Readings in Psychology and Culture 2(1). https://doi.org/10.9707/2307-0919. 1116

Schwartz SH (2014) National culture as value orientations: consequences of value differences and cultural distance. Handbook of the Economics of Art and Culture, Elsevier, Volume 2, Chapter 20, p. 548-584. https://www.researchgate. net/publication/274567696_National_Culture_as_Value_Orientations_ Consequences_of_Value_Differences_and_Cultural_Distance. Accessed 25 June 2019.

Schwartz SH, Bilsky W (1987) Toward a universal psychological structure of human values. J Pers Soc Psychol 53(3):550-562

Schweizerische Eidgenossenschaft (2016). Botschaft zur internationalen Zusammenarbeit 2017-2020. https://www.admin.ch/opc/de/federal-gazette/ 2016/2333.pdf. Accessed 25 June 2019

Sevin E, Boisen M, Kavaatzis M, Givers R (2018) Nation Branding Perspectives. Definitions, Concepts, Theory. The Place Brand Observer. https:// placebrandobserver.com/theory/nation-branding-perspectives/. Accessed 25 June 2019.

Smith PB et al (2002) Cultural values, sources of guidance and their relevance to managerial behavior. A 47-nation study. Journal of Cross-Cultural Psychology 33(2):188-208

SRF (2018) IKRK-Präsident Peter Maurer zwischen den Fronten, https://www.srf. ch/sendungen/samstagsrundschau/ikrk-praesident-peter-maurer-zwischenden-fronten. Accessed 25 June 2019.

Szvircsev TT, Wenger A (2018) Sicherheit 2018. Aussen-, Sicherheits- und Verteidigungspolitische Meinungsbildung im Trend. http://www.css.ethz.ch/ content/dam/ethz/special-interest/gess/cis/center-for-securities-studies/pdfs/ SS2018.pdf. Accessed 25 June 2019.

Tool M (1994) John Dewey. G. M. Hodgson (Ed.). The Elgar Companion to Institutional and Evolutionary Economics. 1, 152-157.

\section{Publisher's Note}

Springer Nature remains neutral with regard to jurisdictional claims in published maps and institutional affiliations.

\section{Submit your manuscript to a SpringerOpen ${ }^{\circ}$ journal and benefit from:}

- Convenient online submission

- Rigorous peer review

- Open access: articles freely available online

- High visibility within the field

- Retaining the copyright to your article

Submit your next manuscript at $>$ springeropen.com 